\title{
Erratum to: Estimation of Relationship Between Domains of ICT Semantic Network
}

\author{
Ravil I. Mukhamediev, Ramiz M. Aliguliyev, \\ and Jelena Muhamedijeva
}

\section{Erratum to: \\ Chapter "Estimation of Relationship Between Domains of ICT Semantic Network" in: D.A. Alexandrov et al. (Eds.): Digital Transformation and Global Society, CCIS 745, https://doi.org/10.1007/978-3-319-69784-0_11}

The book was inadvertently published with incorrect chapter author's family name. This information has been updated from "Aligulyev" to "Aliguliyev" to the initially published version of chapter 11 . 